\title{
Augmented gastrin responses in diabetic patients with vagal neuropathy
}

\author{
A. Kanatsuka, M. Osegawa, T. An, T. Suzuki, N. Hashimoto and H. Makino \\ Second Department of Internal Medicine, Chiba University School of Medicine, Chiba, Japan
}

\begin{abstract}
Summary. We evaluated serum gastrin responses to a test meal in normal subjects and diabetic patients with or without vagal neuropathy. Vagal neuropathy was defined as a heart rate variation during deep breathing of $<9$ beats $/ \mathrm{min}$. Forty-three percent (54 out of 124) of the diabetic patients had abnormal heart rate variation, compared with $5 \%$ ( 3 out of 53 ) of the normal subjects. Serum gastrin responses to a test meal were examined in 17 normal subjects, 20 out of 70 diabetic patients without vagal neuropathy and 17 out of 54 diabetic patients with vagal neuropathy. Meal-stimulated gastrin levels were
\end{abstract}

significantly higher in the diabetic patients with vagal neuropathy than in the normal subjects, while the findings in the diabetic patients without vagal neuropathy were similar to those in normal subjects. These data suggest that augmented gastrin responses are due to vagal denervation induced by autonomic neuropathy.

Key words: Diabetes mellitus, gastrin responses, autonomic neuropathy, heart rate variation, gastroparesis diabeticorum.
Upper gastrointestinal symptoms in patients with diabetes pose a difficult diagnostic problem, since there is no simple, non-invasive, readily repeated test for detecting gastric atony. It is thought that delayed gastric emptying in diabetes is due to vagal neuropathy $[1,2]$, although, unfortunately, there is no simple test of the integrity of parasympathetic nerves to the stomach. In contrast, parasympathetic cardiac damage can be detected easily by recording heart rate variations during deep breathing [3]. Feldman et al. [4] observed that many patients with long-standing insulin-dependent diabetes had delayed gastric emptying and enhanced serum gastrin responses to intragastrically infused nutrients, presumably because of vagal neuropathy. We sought to develop a simple test, evaluating gastrin responses to a test meal in diabetic patients, that would identify patients with early evidence of vagal neuropathy involving the stomach.

\section{Patients and methods}

We measured heart rate variation in 53 non-diabetic subjects and in 124 diabetic patients diagnosed by the diagnostic criteria of the National Institutes of Health [5]. Clinical details are shown in Table 1. The subjects were connected to an electrocardiometer, rested supine for a few minutes and then heart rate variation was recorded during deep breathing at a regular rate of 6 deep breaths $/ \min (5 \mathrm{~s} \mathrm{in,} 5 \mathrm{~s}$ out $)$ for $1 \mathrm{~min}$ [3]. Heart rate variation on deep breathing was assessed by measuring the difference between maximum and minimum heart rates (in beats $/ \mathrm{min}$ ). The diabetic patients were divided into two groups depending on the presence of vagal neuropathy. Vagal neuropathy was defined as heart rate variation during deep breathing of $<9$ beats $/ \mathrm{min}$. Serum gastrin responses to a test meal were measured in 17 out of the 53 control subjects, 20 out of the 70 diabetic patients without vagal neuropathy and 17 out of the 54 diabetic patients with vagal neuropathy. Among the 17 control subjects, the 20 patients without vagal neuropathy and the 17 patients with vagal neuropathy, there were no differences in age or percentage of ideal body weight (Table 1). The average duration of the disease in patients with vagal neuropathy was longer than in patients without, but there were no statistically significant differences between the two groups. Increased heart rates were seen in the diabetic patients with vagal neuropathy and heart rate variation during deep breathing was greatly diminished. Three out of the 17 diabetic patients with vagal neuropathy had gastro-intestinal symptoms of nausea, recurrent vomiting and diarrhoea. The others in this group and all diabetic patients without vagal neuropathy had no gastro-intestinal symptoms. No subject undergoing the test had renal insufficiency. Blood samples were obtained before (basal), 30 and $60 \mathrm{~min}$ after oral administration of a canned fluid diet (Okunos-A, Okunos, Hirakawacho, Tokyo). This consists of $9.8 \mathrm{~g}$ protein, $28.6 \mathrm{~g}$ carbohydrate and $5.2 \mathrm{~g}$ fat. The volume was $200 \mathrm{ml}$ and the $\mathrm{pH}$ approximately 6.3 . Sera were stored at $-20^{\circ} \mathrm{C}$ until assayed. Serum gastrin levels were measured by radioimmunoassay, using a gastrin radioimmunoassay kit (CIS; Commissariat à l'Energie Atomique, Gif-sur-Yvette, France) [6]. The antiserum used in the assay allows correct recognition of human big gastrin. Cross-reactivity with pentagastrin was $<10^{-3}$, and with the octapeptide of cholecystokinin and secretin was $<10^{-5}$. In 17 out of the 20 diabetic patients without vagal neuropathy and 14 out of the 17 diabetic patients with vagal neuropathy, gastric parietal cell antibody was evaluated by an indirect immunofluorescence technique [7], using Wistar rat stomach.

For statistical analysis, Student's t-test and the Mann-Whitney $\mathrm{U}$ test were used as appropriate. 
Table 1. Characteristics of subjects in whom gastrin responses to a test meal were evaluated

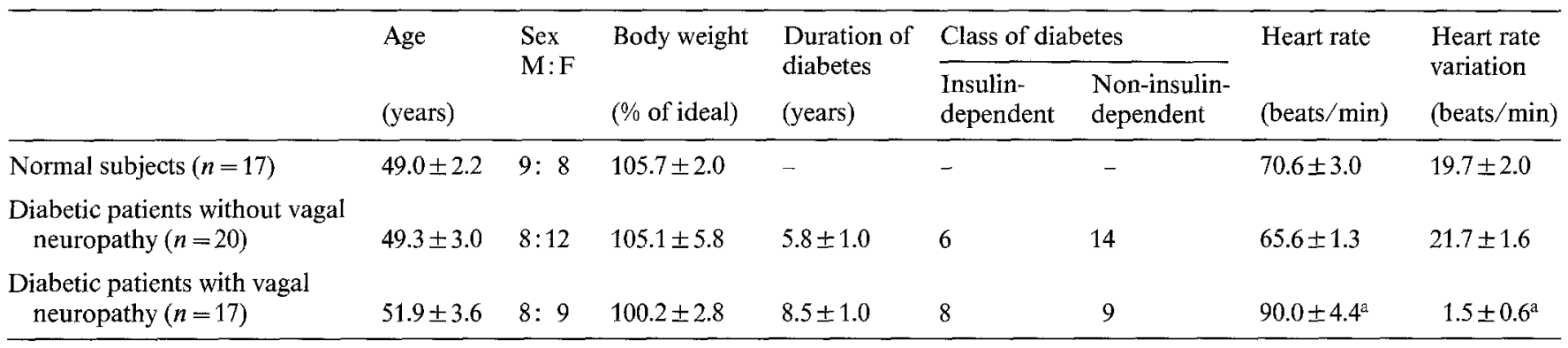

Results expressed as mean \pm SEM.

${ }^{\text {a }} p<0.001$, compared with levels in normal subjects

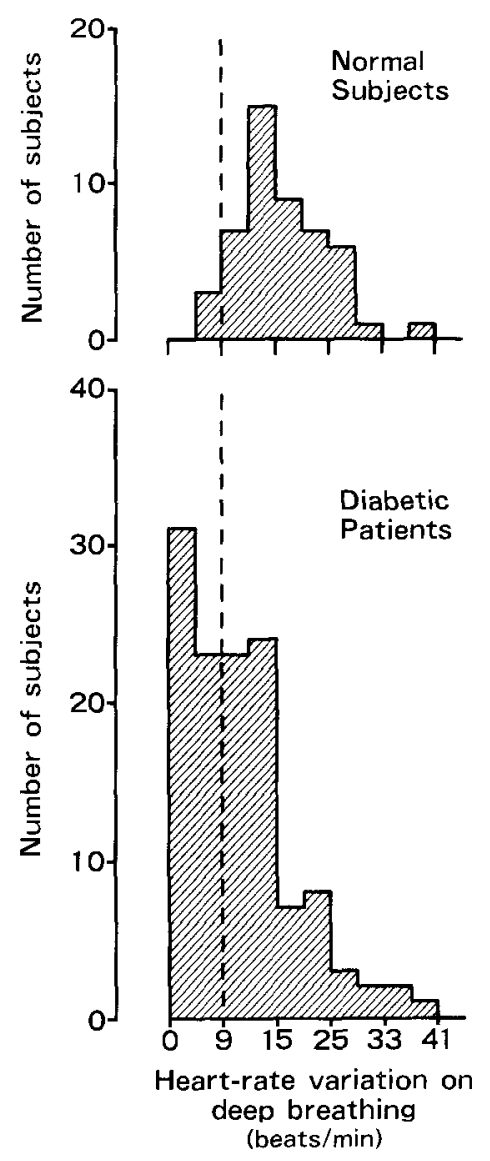

Fig. 1. Responses of heart rate variation on deep breathing in 53 nondiabetic subjects and in 124 diabetic patients. The vertical dotted line indicates the lower limits of normal which were determined by Mackay et al. [3]. The heart rate variations in the diabetic patients were significantly different from those in the non-diabetic subjects $(p<0.01)$

\section{Results}

Figure 1 shows heart rate variation on deep breathing in the non-diabetic and diabetic subjects. Forty-three percent of diabetic patients (54 out of 124) had abnormal heart rate variation scores compared with only $5 \%$ of non-diabetic subjects ( 3 out of 53). Using the MannWhitney $U$ test, the results of heart rate variation were significantly different from the findings in the non-diabetic subjects $(p<0.01)$.

Basal gastrin levels in normal subjects averaged $48.0 \pm 4.4 \mathrm{pg} / \mathrm{ml}$ and serum gastrin increased significantly to $83.8 \pm 9.3 \mathrm{pg} / \mathrm{ml} 30 \mathrm{~min}$ after a test meal (Fig. 2). Similarly, in diabetic patients with or without vagal neuropathy, serum gastrin was stimulated significantly by a test meal. Basal and meal-stimulated gastrin levels were significantly higher in diabetic patients with vagal neuropathy than in normal subjects and diabetic patients without vagal neuropathy, while levels in diabetic patients without vagal neuropathy were similar to those in normal subjects. Using the Mann-Whitney $\mathrm{U}$ test (Fig.3), basal gastrin levels and gastrin responsiveness to the test meal were significantly greater in diabetic patients with vagal neuropathy than in normal subjects and diabetic patients without vagal neuropathy $(p<0.01)$. Gastric parietal cell antibody was present in one of the 17 patients without vagal neuropathy and in two of the 14 patients with vagal neuropathy. Enhanced gastrin responses were observed only in one of the three patients and this patient also had abnormal heart rate variation.

\section{Discussion}

Augmented serum gastrin responses to test meals were evident in about half our diabetic patients with vagal neuropathy diagnosed by heart rate variation during deep breathing. As the control subjects showed a significant response in serum gastrin levels to the test meal, this test is a valuable way of assessing gastrin responsiveness. Among various foods tested, protein was the most potent stimulant of gastrin release $[8,9]$. Gastrin responses in diabetic patients without vagal neuropathy were similar to those in the non-diabetic subjects.

Mackay et al. [3] reported that detecting autonomic neuropathy in diabetic patients by the heart rate responses to deep breathing provided a quantitative assessment of the degree of autonomic damage and that this is the simplest test of autonomic function, suggesting that loss of heart rate variation is due most probably to vagal neuropathy. 


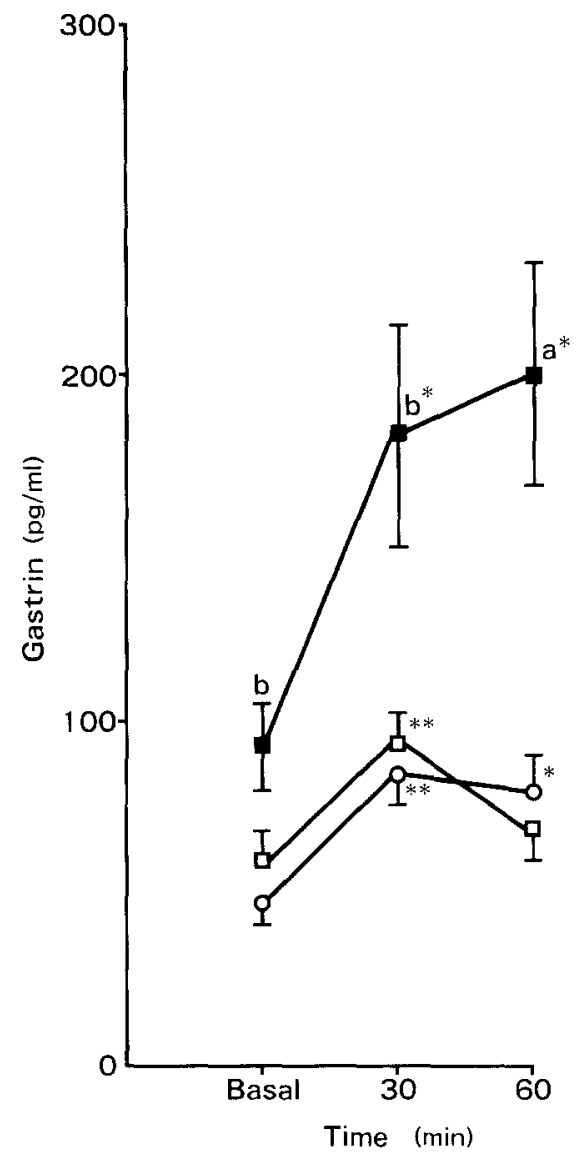

Fig. 2. Mean serum gastrin levels in response to a test meal in 17 normal subjects $\left(\mathrm{O}^{-} \mathrm{O}\right), 20$ diabetic patients without vagal neuropathy $(\square-\square)$ and 17 diabetic patients with vagal neuropathy ( $-\square)$. At $0 \mathrm{~min}$, basal gastrin was measured and the test meal was then administered orally. Values are given as mean \pm SEM. $* * p<0.001$ and * $p<0.01$, compared with serum gastrin levels at $0 \mathrm{~min}$ in each group. ${ }^{\mathrm{a}} p<0.001,{ }^{\mathrm{b}} p<0.01$, compared with serum gastrin levels in normal subjects at each sampling time

The findings of enhanced gastrin responses to a test meal in the diabetic patients with vagal neuropathy supports the thesis that hyper-responsiveness of gastrin to a test meal in diabetic patients may be due to vagal denervation. However, we cannot exclude the possibility that it might be due to differences in acid secretion, because gastric acid was not examined in this study. Feldman et al. [4] observed hypergastrinaemia in long-standing insulin-dependent diabetic patients who secreted less gastric acid than non-diabetic subjects, suggesting that diabetic patients had a hypergastrinaemic response to food, presumably because of vagal neuropathy. On the other hand, hypergastrinaemia was reportedly higher in duodenal ulcer patients after vagotomy [10,11]. Serum gastrin levels were also increased in dogs after vagotomy $[12,13]$. These observations support our thesis that in diabetic patients with vagal neuropathy, enhanced gastrin responses to a test meal may be mostly due to vagal denervation per se. Enhanced gastrin responses to a test meal were observed only in about half the diabetic patients with vagal neuropathy and in the other pat-
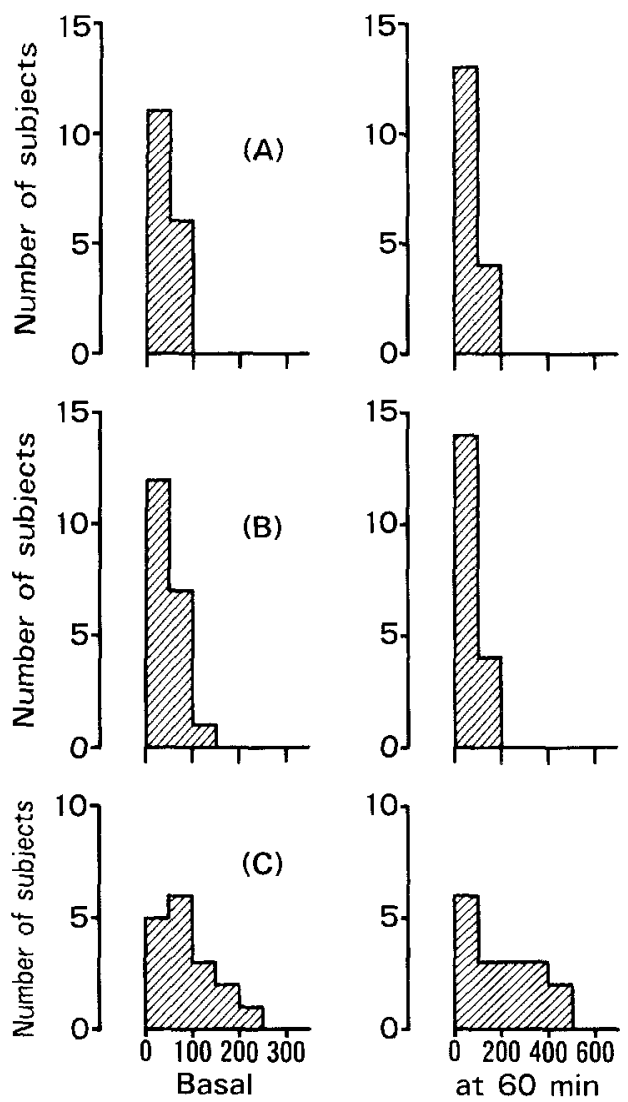

Gastrin (pg/ml)

Fig. 3 A-C. Basal gastrin levels and gastrin levels at $60 \mathrm{~min}$ in A normal subjects, $\mathbf{B}$ diabetic patients without vagal neuropathy and $\mathbf{C}$ diabetic patients with vagal neuropathy. Using the Mann-Whitney $U$ test, in diabetic patients with vagal neuropathy basal gastrin levels and gastrin levels at $60 \mathrm{~min}$ were significantly different from normal subjects and diabetic patients without vagal neuropathy (basal gastrin levels: $p<0.01$, gastrin levels at 60 min: $p<0.01$ )

ients, the same degree of response as seen in normal subjects and diabetic patients without vagal neuropathy. In patients with peptic ulcer, hypergastrinaemia is often detected not only after truncal vagotomy but also after selective proximal vagotomy [14-16]. The vagal inhibitory pathway for gastrin release may be located in the proximal stomach [14]. Thus, the vagus in a portion of the stomach may be denervated in some diabetic patients with vagal neuropathy, and hyper-responsiveness of gastrin would ensue.

As the test meal in our studies had a pH 6.3, intragastric acid concentration might not be relevant. It is possible that achlorhydria secondary to vagal neuropathy caused an increased gastrin response, as seen in patients with pernicious anaemia. However, Feldman et al., who controlled gastric $\mathrm{pH}$ by titration in vivo, found that gastrin responses to food were greater after vagotomy compared with before vagotomy in patients with duodenal ulcer [14]. Enhanced gastrin responses in diabetic patients with vagal neuropathy are therefore unlikely to be simply due to reduction in gastric acidity. 
Gastric parietal cell antibody was observed in three of the 31 patients examined and only one had increased gastrin responses to a test meal and this patient also had vagal neuropathy. It is, therefore, unlikely that increased gastrin responses in diabetic patients with vagal neuropathy were induced by achlorhydria due to atrophic gastritis. Renal failure is reportedly one cause of hypergastrinaemia in diabetic patients [17] but patients with renal insufficiency were excluded from our study.

Finally, many patients with gastroparesis diabeticorum are free of gastrointestinal symptoms, although some develop a syndrome characterized by nausea and recurrent vomiting [1]. In this study, only three patients with both vagal neuropathy and enhanced gastrin responses complained of these symptoms and five patients with both signs did not complain of gastrointestinal symptoms. Thus, augmented gastrin responses in diabetic patients with vagal neuropathy may be the early manifestation of gastroparesis diabeticorum.

Acknowledgments. We thank Dr. S. Yoshida and Dr. J. Kasanuki, Chiba University for pertinent suggestions, and Drs. K. Aida, H. Iwaoka, R. Matsumura, M.Mimura, A.Seya, T.Sugiyama, M.Taira, and H. Wakita, Chiba University and Drs. M. Yokota, H. Matsuoka, and K. Matsumoto, Narita Red Cross Hospital for assistance. We are also grateful to M. Ohara, Kyushu University for comments on the manuscript and M.Takayama and staff of Narita Red Cross Hospital, Minamihama Clinic and Hanazono Clinic for technical assistance.

\section{References}

1. Clarke BF, Ewing DJ, Campbell IW (1979) Diabetic autonomic neuropathy. Diabetologia 17: 195-212

2. Kassander $P$ (1958) A symptomatic gastric retention in diabetics (gastroparesis diabeticorum). Ann Intern Med 48: 797-812

3. Mackay JD, Page M, Mo B, Cambridge J, Watkins PJ (1980) Diabetic autonomic neuropathy. The diagnostic value of heart rate monitoring. Diabetologia 18: 471-478

4. Feldman M, Carbett DB, Ramsey EJ, Walsh JH, Richardson CT (1979) Abnormal gastric function in long-standing, insulin-dependent diabetic patients. Gastroenterology 77:12-17

5. National Diabetes Data Group (1979) Classification and diagno- sis of diabetes mellitus and other categories of glucose intolerance. Diabetes 28: 1039-1057

6. Kaess H, Mariadec B (1973) Dosage radioimmunologique de la gastrine mise au point du dosage et résultats cliniques. In: Colloque sur le radioimmunodosage et les méthodes connexes en médecine clinique et dans la recherche. Agence internationale de l'energie atomique, Istanbul

7. Irvine WJ, Clark BF, Scarth L, Cullen DR, Duncan LJP (1970) Thyroid and gastric autoimmunity in patients with diabetes mellitus. Lancet 2: 163-168

8. Korman MG, Soveny C, Hansky J (1971) Effect of food on serum gastrin evaluated by radioimmunoassay. Gut 12: 619-624

9. Ganguli PC (1970) The effect of protein, carbohydrate, and fat on plasma gastrin concentrations in human subjects. Gut 11: 1061 (Abstract)

10. Stadil F (1972) Effect of vagotomy on gastrin release during insulin hypoglycemia in ulcer patients. Scand J Gastroenterol 7: 225-231

11. Korman MG, Hansky J, Scott PR (1972) Serum gastrin in duodenal ulcer. III. Influence of vagotomy and pylorectomy. Gut 13: $39-42$

12. Korman MG, Brough BJ, Hansky J (1972) Gastrin and acid studies in the pouch dog. Scand J Gastroenterol 7: 525-529

13. Shiratori T, Okabayashi T, Nishigori M, Sakurai R, Shimono Y (1977) Effect of various types of vagotomy on gastrin release and gastric secretion in dog. Tohoku J Exp Med 122: 209-222

14. Feldman M, Dickerman RM, McClelland RN, Cooper KA, Walsh JH, Richardson CT (1979) Effect of selective proximal vagotomy on food-stimulated gastric acid secretion and gastric release in patients with duodenal ulcer. Gastroenterology 76: 926-931

15. Stadil F, Rehfeld JF (1974) Gastrin response to insulin after selective, highly selective, and truncal vagotomy. Gastroenterology 66 : 7-15

16. Jaffe BM, Glendinneu BG, Clark RJ, Williams JA (1974) The effect of selective and proximal gastric vagotomy on serum gastrin. Gastroenterology 66: 944-953

17. Korman MG, Laver MC, Hansky J (1972) Hypergastrinemia in chronic renal failure. Br Med J I: 209-210

Received: 30 July 1982

and in revised form: 31 January 1984

Dr. Azuma Kanatsuka

Second Department of Internal Medicine

Chiba University School of Medicine

1-8-1 Inohana

Chiba 280

Japan 